DOI: https://doi.org/10.47405/mjssh.v6i8.953

\begin{tabular}{|c|c|}
\hline 4.581 & Malaysian Journal of Social Sciences and Humanities (MJSSH) \\
\hline $\begin{array}{l}\text { Malaysian Journal of } \\
\text { Social cciences and }\end{array}$ & Volume 6, Issue 8, August 2021 \\
\hline (MJ-SSH) & e-ISSN : 2504-8562 \\
\hline & $\begin{array}{l}\text { Journal home page: } \\
\text { www.msocialsciences.com }\end{array}$ \\
\hline
\end{tabular}

\title{
Intersectionality: Implikasi Proses Sosialisasi Politik terhadap Budaya Politik Wanita Cina di Semenanjung Malaysia
}

\author{
Nurul Asmaa Ramli'1, Kartini Aboo Talib@Khalid1, Hanim Ismail1 \\ ${ }^{1}$ Institut Kajian Etnik, Universiti Kebangsaan Malaysia (UKM) \\ Correspondence: Nurul Asmaa binti Ramli (tesisphdasmaa@gmail.com)
}

\begin{abstract}
Abstrak
Budaya politik wanita Cina di Semenanjung Malaysia bersifat pasif. Fenomena ini dapat dilihat melalui bilangan wanita Cina antaranya di dalam Parlimen dan DUN. Malahan bilangan wanita Cina di peringkat pembuat keputusan dalam parti berorientasikan masyarakat Cina seperti DAP serta MCA masih lagi rendah, walaupun sistem kuota 30 peratus wanita telah dibentuk. Proses sosialisasi politik melalui agen sosialisasi politik merupakan antara indikator penting yang mempengaruhi budaya politik wanita Cina di Semenanjung Malaysia. Agen sosialisasi ini dilihat tidak berdiri sendiri dan saling berkait seperti yang diketengahkan melalui teori intersectionality dan telah memberikan kesan berbeza kepada wanita. Kajian kualitatif ini mengenal pasti agen sosialisasi politik melalui proses sosialisasi politik, yang telah mempengaruhi budaya politik wanita Cina di Semenanjung Malaysia. Temu bual secara intensif telah dijalankan ke atas tujuh orang informan dalam kalangan perwakilan wanita Cina, seorang ahli politik lelaki, aktivis wanita Cina dari Organisasi Bukan Kerajaan (NGO) dan ahli akademik. Hasil temu bual dianalisis di mana proses transkripsi temubual telah dikodkan dan ditemakan. Tema ini kemudiannya telah dibahagikan kepada dua iaitu agen sosialisasi politik lingkaran dalaman dan agen sosialisasi politik lingkaran luaran. Agen sosialisasi lingkaran dalaman terdiri daripada pendidikan, ekonomi, budaya, agama, keluarga serta gender. Agen sosialisasi lingkaran luaran pula terdiri daripada NGO/persatuan, parti politik dan masyarakat. Model Agen Sosialisasi Politik Wanita Cina melalui dimensi intersectionality turut dibangunkan untuk menggambarkan hubung kait agen sosialisasi politik wanita Cina di Semenanjung Malaysia.
\end{abstract}

Kata kunci: wanita Cina, budaya politik, proses sosialisasi politik, Intersectionality

\section{Intersectionality: The Implication of The Political Socialization Process Towards the Political Culture of Chinese Women in Peninsular Malaysia}

\begin{abstract}
The political culture of Chinese women in peninsular Malaysia is passive. This phenomenon can be seen through the number of Chinese women in the Parliament and DUN level. Besides, the number of Chinese women at the decision making level in Chinese-oriented political parties such as DAP and MCA is still low, although the $30 \%$ women quota has been implemented. The process of political socialization through the political socialization agents is an important indicator influencing the political culture of Chinese women in Peninsular Malaysia. These agents of socialization has been seen to not stand on its own, and has always intertwined as it has been proposed in the theory of intersectionality and has affected women differently. This qualitative study has identified the political socialization agents through the process of political socialization that has influenced the political culture of Chinese
\end{abstract}


women in Peninsular Malaysia. Intensive interviews were conducted on seven informants, mainly, representatives of women within the Chinese community, a male politician, a female Chinese activist affiliated with a Non-Governmental Organization (NGO), and an academician. The results of the interviews were then analyzed, where the interviews were transcribed, codified and then categorized into themes. These themes were then divided into two, the first being internal political socialization agents, and the second being external political socialization agents. Internal political socialization agents consists of education, economy, culture, religion, family, as well as gender. External political socialization agents consists of NGOs, organizations, political parties, and the community. The Chinese Women Political Socialization Agent Model was developed through the dimension of intersectionality to depict the connection of political socialization agents within Chinese women in Peninsular Malaysia.

Keywords: Chinese women, political culture, political socialization process, intersectionality

\section{Pengenalan}

Malaysia merupakan negara yang mempunyai penduduk pelbagai etnik dengan komposisi etnik terbesar di Malaysia adalah terdiri daripada etnik Melayu, Cina dan India. Kepelbagaian etnik di Malaysia ini adalah rentetan dari kemasukan buruh asing yang telah dibawa masuk oleh penjajah British. Kepelbagaian etnik ini telah membentuk keunikan tersendiri kerana telah menimbulkan budaya, bahasa, agama dan cara hidup yang berbeza. Aspek multidimensi ini telah menjadi konstruksi yang boleh mempengaruhi budaya politik rakyat Malaysia termasuklah wanita seperti yang diketengahkan melalui teori intersectionality. Bilge dan Collins (2016: 2) mendefinisikan teori intersectionality sebagai cara memahami dan menganalisis dunia melalui konteks individu dan pengalaman manusia yang bersifat kompleks. Peristiwa serta kehidupan sosial dan politik bukan hanya dibentuk oleh satu faktor malah dibentuk oleh pelbagai faktor yang saling mempengaruhi. Manakala Aurora Levins Morales pula menyatakan bahawa pengalaman wanita sentiasa berubah mengikut peredaran masa dan menyarankan agar wanita dilihat dalam dalam konteks multidimensi dan pengalaman wanita mestilah dikaitkan dengan aspek etnik, warna kulit, umur, kelas sosial, budaya, sejarah, lokasi geografi, bahasa dan status kewarganegaraan (Samuels \& Ross Sheriff, 2008, p.5).

Sarjana Bastia (2014), Freidenvall (2016), Hankivsky (2012) dan Jang (2018) menyatakan bahawa teori intersectionality ini telah mula dicetuskan oleh Kimberle Williams Crenshaw. Crenshaw (1989) menggunakan konsep intersectionality untuk memahami bagaimana hubungan persilangan antara gender dan etnik telah membatasi wanita kulit hitam dalam pasaran buruh di Amerika Syarikat. Kurangnya pemahaman mengenai intersectionality ini telah menyebabkan wanita kulit hitam berdepan dengan pengalaman di diskriminasi. Tambahan lagi, kelompok identiti yang bersifat dominan atau majoriti bilangannya telah mengecualikan atau meminggirkan kumpulan identiti yang berbeza atau minoriti bilangannya (Crenshaw, 1991, p.1242). Sebagai contoh, masyarakat kulit putih dan kulit hitam di Amerika Syarikat. Faktor gender dan etnik melalui hujah Crenshaw $(1989,1991)$ ini merupakan faktor penting yang telah diberi keutamaan dalam membincangkan isu berkaitan penindasan wanita dan sentimen berasaskan perkauman. Tekanan ke atas faktor gender dan etnik telah menjadi asas kepada bentuk penindasan sehingga mengabaikan faktor penting yang lain. Namun begitu, fenomena ini telah dikritik oleh ramai sarjana kerana bukan faktor gender dan etnik sahaja yang telah memberi pengalaman berbeza kepada wanita. Namun terdapat juga faktor lain yang turut mempengaruhi pengalaman mereka seperti faktor kelas, agama serta budaya patriarki (Fathi, 2017: 29).

Kebanyakan kajian lepas mengenai gender dan aplikasi konsep intersectionality menekankan aspek faktor. Aspek faktor yang dilihat adalah merangkumi faktor yang mempengaruhi tindak tanduk dan penglibatan politik individu terutamanya wanita. Melalui hasil kajian Joshi (2011), Brown (2014), Finlay et al. (2019) dan Moreau (2019), faktor umur, pendidikan, jumlah pendapatan, kecenderungan politik, agama, parti politik, kewarganegaraan, status ekonomi serta pengalaman diskriminasi saling bersilang dan berkait dan mempengaruhi penglibatan dalam lapangan politik. Namun begitu, Joshi (2011), Brown (2014), Finlay et al. (2019) dan Moreau (2019) hanya membincangkan indikator faktor sahaja dan tidak mengambil kira proses sosialisasi politik. Proses sosialisasi politik merupakan proses 
penting yang perlu diambil kira dalam membincangkan mengenai tingkah laku politik, penglibatan politik mahupun budaya politik. Menurut Siti Rohana et al. (2008: 699), proses sosialisasi politik adalah suatu proses yang membolehkan individu mengenali sistem politik yang kemudiannya akan mempengaruhi persepsi mereka terhadap politik serta reaksi terhadap gejala politik. Proses sosialisasi politik melibatkan fenomena makro dan mikro yang saling berkait. Proses sosialisasi politik di peringkat makro ialah bagaimana politik, masyarakat politik dan sistem politik menerapkan norma dan amalan yang sesuai dalam kalangan warganegara, penduduk, atau ahli. Manakala proses sosialisasi politik di peringkat mikro adalah corak serta proses individu dalam pembangunan politik dan pembelajaran serta membina hubungan dalam konteks politik (Sapiro, 2004, p. 2-3). Oleh itu kajian ini menggunakan teori intersectionality dalam membincangkan indikator agen sosialisasi politik dan cabaran politik yang akan mempengaruhi tingkah laku politik individu yang kemudiannya akan membentuk tingkah laku politik kumpulan yang diterjemahkan kepada budaya politik wanita Cina di Semenanjung Malaysia.

Menurut Ahmad Nidzamuddin (2002) budaya politik adalah berkaitan satu perlakuan, tingkah laku, penglibatan, persepsi, kepercayaan, jangkaan dan harapan anggota masyarakat dalam lingkungan politik masyarakatnya. Budaya politik merangkumi perihal sikap, nilai, orientasi, pendapat, tanggapan dan perasaan terhadap politik. Bagi individu, budaya politik berfungsi sebagai panduan kawalan terhadap tindakan politik yang efektif. Manakala bagi kumpulan pula, budaya politik memainkan peranan untuk membekalkan suatu struktur nilai dan pertimbangan rasional yang sistematik bagi menentukan keberkesanan tindakan yang dilakukan oleh institusi dan organisasi politik. Budaya politik melibatkan perasaan subjektif seseorang atau sesuatu kumpulan terhadap penerimaan atau penolakan sesuatu identiti komuniti dan kepatuhan terhadap pemimpin (Junaidi Awang \& Mohd Fuad, 2015, p.12).

Manakala menurut, Mohd Mahadee (2018: 470) budaya politik merupakan suatu unsur yang tidak bersifat statik dan boleh berubah berdasarkan kepada keadaan, masa, perubahan teknologi dan persekitaran. Oleh itu dapat disimpulkan bahawa budaya politik ini merupakan orientasi yang berkaitan dengan politik serta tidak bersifat berubah-rubah mengikut keadaan dan masa.

Budaya politik wanita Cina di Malaysia tidak boleh diabaikan kerana rata-rata kajian mengenai budaya politik di Malaysia banyak berkisar kepada budaya politik Melayu. Hal ini dapat dilihat melalui hasil karya Mohd Faidz et al. (2011), Noor Sulastry (2014), Mohd Mahadee (2018) serta Ilyas Abdullah (2020). Mohd Mahadee (2018) dalam karyanya mengkaji mengenai Budaya Politik Kontemporari Masyarakat Melayu di Malaysia: Satu Penilaian Kritis manakala Noor Sulastry (2014) pula membincangkan mengenai Hegemoni Budaya Politik Melayu. Manakala Mohd Faidz et al. (2011) mengupas mengenai Pengaruh Nasionalisme Melayu Mewarnai Budaya Politik Melayu. Berbeza dengan Ilyas Abdullah (2020) yang telah membincangkan mengenai Transformasi Budaya Politik Melayu Terengganu. Dalam konteks kajian mengenai budaya politik seolah-olah berada dalam pengaruh anak watan sedangkan Malaysia terdiri daripada penduduk pelbagai etnik. Budaya politik selain anak watan kurang dibicarakan termasuklah budaya politik masyarakat Cina.

Malahan keperatusan wanita Cina yang berada dalam Parlimen mahupun DUN masih lagi rendah. Hal ini dapat dilihat melalui keperatusan wanita Cina di dalam Parlimen pada Pilihan Raya Umum ke-13 adalah sebanyak 2.3 peratus dan angka ini telah meningkat kepada 4.5 peratus selepas Pilihan Raya Umum ke-14. Walaupun berlaku peningkatan peratusan wanita Cina di dalam Parlimen pada Pilihan Raya Umum ke-14. Namun jumlah ini masih kecil, malah kadar peningkatan adalah dalam kadar yang rendah dan perlahan. Berbeza pula dengan bilangan wanita Cina yang berada di dalam Dewan Undangan Negeri. Bilangan wanita Cina yang telah menganggotai DUN pada Pilihan Raya Umum ke13 adalah sebanyak 3.8 peratus dan keperatusan ini telah menurun kepada 3.4 peratus pada Pilihan Raya Umum ke-14. Jika diteliti, keperatusan bilangan wanita Cina pada pertengahan tahun 2019 adalah mencatat sebanyak 22.4 peratus dari keseluruhan jumlah penduduk perempuan warganegara Malaysia. Namun peratusan wanita Cina di Parlimen pada Pilihan Raya Umum ke-14 adalah sebanyak 4.5 peratus manakala keperatusan wanita di DUN pada pada Pilihan Raya Umum ke-14 adalah sebanyak 3.4 peratus. Keperatusan bilangan wanita Cina di Parlimen dan DUN ini masih rendah. Jika dibandingkan dengan jumlah penduduk perempuan Cina di Malaysia secara keseluruhannya (Parlimen 
Malaysia 2020). Oleh itu, suara wanita Cina tidak boleh diabaikan kerana mereka diperlukan untuk menyuarakan dan menjaga kepentingan wanita Cina di Malaysia.

Tambahan lagi Malaysia merupakan sebuah negara yang mengamalkan sistem pemerintahan berasaskan demokrasi yang menjunjung prinsip hak asasi manusia. Hal ini dapat dilihat melalui Perlembagaan Persekutuan Malaysia, bahagian II fasal 8 yang membincangkan mengenai hak kesamarataan dalam konteks Malaysia. Sebarang bentuk diskriminasi terhadap warganegara kerana faktor agama, ras, keturunan, tempat lahir atau gender merupakan amalan yang ditentang oleh pihak kerajaan. Namun perkara ini berbeza dengan hak keistimewaan yang di nikmati oleh anak watan. Perkara ini juga telah termaktub dalam Perlembagaan Persekutuan Malaysia melalui Perkara 153. Kelebihan yang telah dinikmati oleh masyarakat Bumiputera adalah rentetan daripada status mereka yang merupakan penduduk asal di seluruh Tanah Melayu serta Sabah dan Sarawak. Maka amalan konsep kesamarataan dalam konteks Malaysia ini juga adalah berbeza di mana masyarakat selain Bumiputera tidak dapat menikmati hak keistimewaan masyarakat Bumiputera. Hak keistimewaan ini adalah merangkumi kuota dalam jawatan perkhidmatan awam, biasiswa, bantuan kemudahan pendidikan serta permit perniagaan dan perdagangan (Ku Hasnita et al., 2018, p. 71). Rentetan itu, pengalaman yang telah dihadapi oleh wanita Melayu selaku masyarakat Bumiputera tidak boleh disamakan dengan wanita Cina. Oleh itu, kajian ini mengambil kira aspek multidimensi untuk melihat agen sosialisasi politik yang telah mempengaruhi budaya politik wanita Cina di Semenanjung Malaysia.

\section{Sorotan Literatur}

Sorotan kajian lepas yang dibahaskan dalam bab ini telah dibahagikan kepada beberapa tema iaitu situasi wanita dan politik di Malaysia serta lanskap politik masyarakat Cina di Malaysia.

\section{Wanita dan Politik di Malaysia}

Beberapa sarjana tersohor telah mengkaji gender dan politik termasuk Rashila $(1998,2008), \mathrm{Ng}$ (2010), Zahari et al. (2013), Kartini (2014, 2019), Azizan (2015), Mohammad Agus et al. (2016), Nor Rafidah et al. (2017), Fatimi (2019), Ruhana (2017), Maznah (2018), Nur Syakirin dan Zawiyah (2019), Zaireeni (2019), Nik Safiah dan Rokiah (2016), Nur Syakiran dan Zawiyah (2019), Syarifah dan Ummu (2019), Sukhani (2020) dan Dwijayanto et al. (2020). Perbincangan mengenai wanita dan politik ini merangkumi topik mengenai cabaran yang telah dihadapi oleh wanita dalam bidang politik, penglibatan wanita melalui parti politik, usaha pemerkasaan wanita dalam politik di Malaysia serta wanita dan politik dalam kerangka demokrasi. Malah melalui sorotan kajian lepas ini, rata-rata kajian yang membincangkan mengenai wanita dan politik telah menggeneralisasikan wanita kepada semua wanita di Malaysia. Tanpa mengambil kira indikator etnik, agama, budaya, sejarah dan lain-lain. Indikator ini memberi pengalaman yang berbeza kepada wanita dan mempengaruhi penglibatan wanita dalam bidang politik. Oleh itu, hasil kajian mengenai wanita dan politik tanpa mengambil kira indikator ini menjadikan kajian kurang tepat kerana tidak menggambarkan secara terperinci konstruksi sosial wanita di Malaysia yang terdiri daripada pelbagai etnik. Hal ini kerana setiap wanita mempunyai pengalaman yang berbeza-beza rentetan dari orientasi agama, nilai, ideologi, budaya serta sejarah. Malahan, setiap indikator ini harus diambil kira dalam kajian mengenai wanita dan politik agar langkah memahami penglibatan wanita dan politik menjadi lebih relevan.

\section{Lanskap Politik Masyarakat Cina Di Malaysia}

Kajian mengenai lanskap politik masyarakat Cina di Malaysia telah dibincangkan melalui karya James (2001), Ridhuan (2008), Noraini (2009), Lee (2010), Kikue (2013), Ishak (2014), Oh (2014), Amir (2017), Suhana dan Kartini (2017), Junaidi et al. (2017), Nan et al. (2018), Thock Ker dan Tan (2018), Great et al. (2012) serta James dan Taufiq (2019). Tumpuan perbincangan berdasarkan sorotan karya ini adalah berkisar mengenai sejarah penglibatan awal etnik Cina dalam bidang politik, peranan parti MCA dan parti perikatan di peringkat awal kemerdekaan serta perkembangan pola pengundian masyarakat Cina di Malaysia. Dalam konteks ini, penglibatan masyarakat Cina dalam bidang politik 
dikatakan masih berada pada tahap yang rendah semenjak awal kemerdekaan lagi. Parti MCA merupakan parti Cina yang telah mendapat sokongan masyarakat Cina sejak awal kemerdekaan lagi. Namun pola pengundian dan sokongan masyarakat Cina telah berubah kepada DAP. Hal ini kerana parti MCA dan GERAKAN yang merupakan komponen parti BN telah gagal mendapat sambutan dalam kalangan masyarakat Cina kerana dikatakan tidak mampu untuk memperjuangkan aspirasi masyarakat Cina. Rata-rata kajian yang membincangkan mengenai landskap politik masyarakat Cina di Malaysia kurang membincangkan mengenai faktor yang mempengaruhi penglibatan politik serta cabaran yang telah dihadapi oleh masyarakat Cina dalam bidang politik. Malahan kajian mengenai masyarakat Cina dan politik juga kurang mengambil kira dan memberi tumpuan kepada faktor gender.

\section{Metod Kajian}

Kajian ini telah menggunakan kaedah penyelidikan berbentuk kualitatif melalui teknik temu bual intensif. dan pengumpulan data sekunder. Interaksi antara penemubual dan informan melalui proses temu bual membolehkan pengkaji memahami persepsi, perasaan dan pengalaman informan terhadap soalan yang ditanya (Babbie, 2010, p. 318). Temu bual intensif ini dibuat berpandukan kepada soalan separa berstruktur bagi memastikan keseragaman maklumat yang diperoleh bagi menjawab persoalan kajian. Namun nama informan yang telah ditemu bual melalui kajian ini tidak didedahkan. Ini untuk menjaga prinsip anonymous yang bertujuan untuk memastikan keselamatan informan adalah terjamin. Ini juga memberikan kebebasan kepada mereka untuk berkongsi pengalaman, pendapat yang tidak terhad dan ada kalanya pandangan dan emosi mereka boleh menimbulkan kontroversi.

Informan utama yang telah ditemu bual dalam kajian ini adalah seramai 10 orang. Mereka terdiri daripada perwakilan politik wanita Cina, aktivis NGO, ahli akademik serta ahli politik lelaki yang berkhidmat dan berada di Semenanjung Malaysia. Penyelidik menemu bual perwakilan politik wanita Cina kerana mereka aktif dan telah terlibat secara langsung dalam bidang politik sama ada menjawat jawatan penting dalam parti politik, menjadi anggota Dewan Rakyat mahupun Dewan Undangan Negeri di Semenanjung Malaysia. Oleh itu, mereka lebih memahami situasi sebenar dunia politik. Manakala ahli akademik adalah individu yang mempunyai kepakaran dalam budaya politik masyarakat Cina serta aktif menjalankan kajian mengenai budaya politik masyarakat Cina. Aktivis NGO wanita Cina pula dipilih kerana mereka terlibat dalam usaha menjaga hak asasi wanita termasuk wanita Cina. Malahan aktivis NGO juga bekerjasama dan berinteraksi secara langsung dengan ahli politik wanita, parti politik dan juga pihak kerajaan dalam usaha memperkasa wanita yang merangkumi aspek ekonomi, politik dan sosial. Oleh itu, aktivis NGO boleh memberi pendapat dan pandangan berdasarkan pengalaman mereka dalam menilai budaya politik wanita Cina di Semenanjung Malaysia. Sementara pandangan kecil informan lelaki turut dimasukkan kerana beliau secara sukarela menawarkan diri untuk ditemu bual mengenai budaya politik wanita Cina di Semenanjung Malaysia. Ahli politik lelaki merupakan antara individu yang turut terlibat secara langsung dengan ahli politik wanita Cina.

Kenyataan hasil dari temu bual bersama informan direkodkan dan ditranskripsikan melalui salinan verbatim. Tema telah dibina hasil dari temubual bagi memaparkan dapatan hasil transkripsi temu bual bersama informan. Menurut Taylor dan Bogdan (1998) perkara penting dalam proses penemuan dapatan kajian adalah mengenal pasti tema serta membangunkan konsep dan kenyataan umum. Aktiviti pengekodan turut dijalankan dengan tujuan untuk membangunkan serta menginterpretasikan hasil dapatan kajian dari temu bual intensif. Analisis melalui transkripsi dibuat dengan menganalisis kekerapan dan persamaan pandangan yang telah dinyatakan oleh informan utama dan ditemakan. Melalui kajian ini penyelidik turut mempamerkan kenyataan cerita atau storyline seperti direct quotation yang memperlihatkan pengalaman serta luah rasa informan mengenai subjek yang dikaji. Rentetan daripada quotation secara langsung yang telah dicatat secara verbatim ini maka terdapat pengunaan bahasa pasar atau bahasa campuran antara Bahasa Melayu dan Bahasa Inggeris yang telah digunakan oleh informan utama. Di samping itu, kajian ini juga turut memberikan tumpuan penting dalam pengumpulan data sekunder untuk mendapatkan maklumat mengenai sejarah, latar belakang serta gambaran yang lebih jelas mengenai fenomena yang dikaji. Terdapat beberapa sumber utama dari data sekunder yang turut digunakan di mana data ini diperoleh daripada perpustakaan serta ARKIB. 


\section{Hasil Kajian}

Model agen sosialisasi politik wanita Cina di Semenanjung Malaysia melalui dimensi intersectionality seperti rajah 1 telah dibangunkan untuk menggambarkan persilangan dan hubung kait antara agen sosialisasi politik wanita Cina di Semenanjung Malaysia. Hasil temu bual mendapati bahawa agen sosialisasi politik telah mempengaruhi tingkah laku politik serta budaya politik wanita Cina di Semenanjung Malaysia. Agen sosialisasi politik ini telah ditemakan kepada dua bahagian iaitu agen sosialisasi lingkaran dalaman dan agen sosialisasi lingkaran luaran. Agen sosialisasi lingkaran dalaman terdiri daripada pendidikan, ekonomi, keluarga, agama, keluarga serta gender. Agen sosialisasi lingkaran luaran pula terdiri daripada NGO, parti politik dan masyarakat. Agen sosialisasi politik ini dilihat tidak berdiri sendiri malahan saling bersilang dan bertindan. Hal ini kerana sebahagian besar informan telah berkongsi pandangan, di mana terdapat lebih dari satu agen sosialisasi politik yang mempengaruhi tingkah laku politik mereka.

Rajah 1: Model Agen Sosialisasi Politik Wanita Cina melalui Dimensi Teori Intersectionality di Semenanjung Malaysia

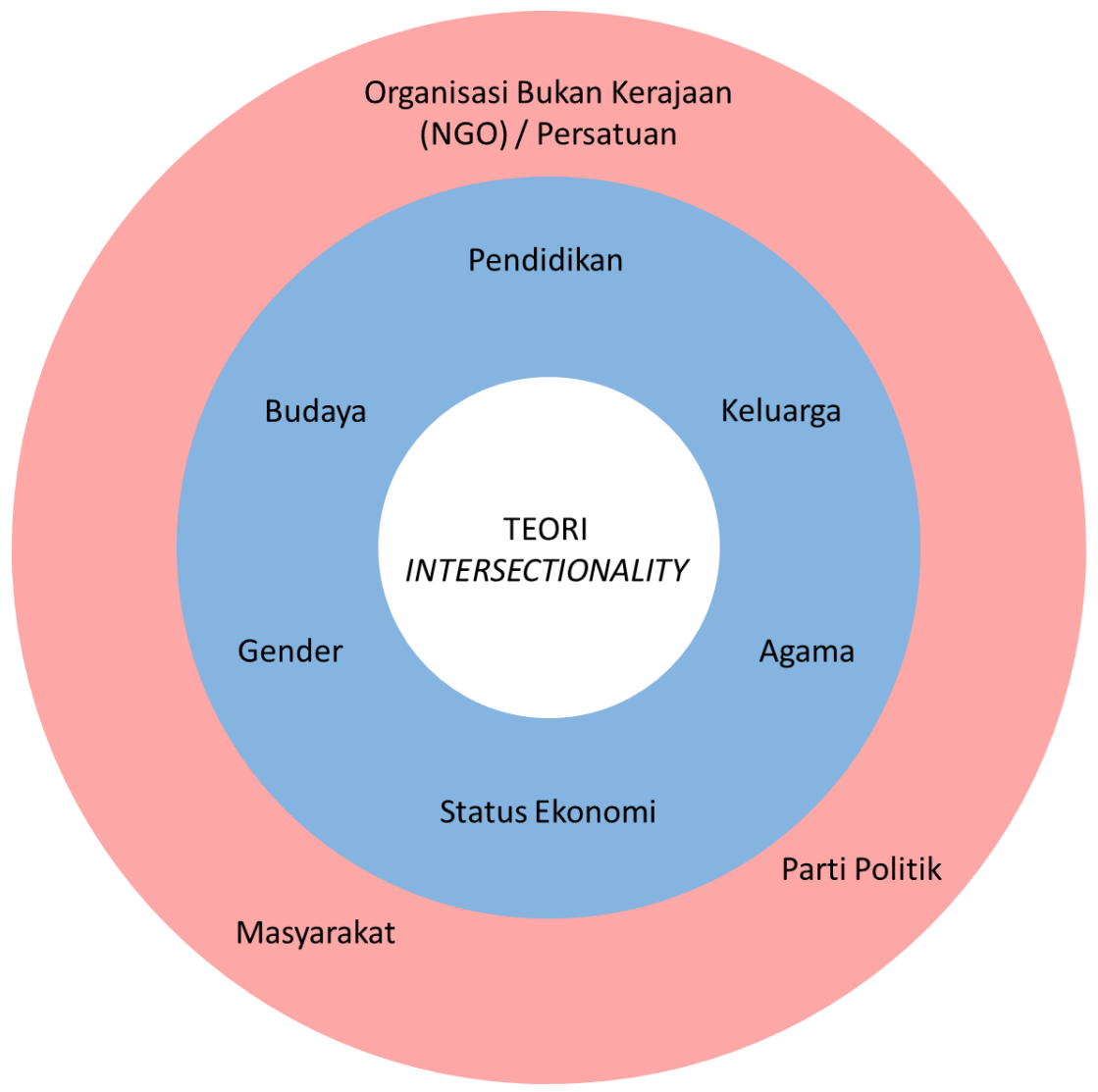

Agen Sosialisasi Politik Lingkaran Dalaman

Agen Sosialisasi Politik Lingkaran Luaran

(Sumber: Ubahsuai Dari Dapatan Kajian Penyelidik) 


\section{Perbincangan Kajian}

\section{Agen Lingkaran Dalaman}

\section{a) Pendidikan}

Pendidikan merupakan antara agen sosialisasi politik yang penting kepada individu. Malahan masyarakat Cina turut mengutamakan pendidikan. Menurut Yingying (2016: 89), pengaruh pemikiran Konfusianisme sangat mementingkan pendidikan dan menekankan adat menghormati guru. Perkara ini dikatakan sudah lama wujud sehingga menjadi amalan baik bagi masyarakat Cina. Tradisi mengutamakan pendidikan serta bahasa ibunda telah diwariskan dari satu generasi kepada generasi terkemudian. Masyarakat Cina harus mempelajari bahasa Cina dan perkara ini telah ditetapkan sebagai pegangan teguh bagi masyarakat Cina seberang laut termasuk di Tanah Melayu. Walaupun pendidikan wanita Cina sebelum ini lebih menekankan aspek pendidikan rumah tangga namun pembaharuan dan gerakan emansipasi wanita di Tanah Besar China turut mengimpak kepada corak pendidikan wanita bukan sahaja di Tanah Besar China malahan di Tanah Melayu.

Melalui kenyataan kebanyakan informan yang telah ditemu bual ini mereka mempunyai tahap pendidikan yang tinggi di mana mereka mempunyai Ijazah Sarjana Muda serta Ijazah Sarjana. Oleh itu kebanyakan dari mereka mempunyai status ekonomi yang baik berdasarkan kerjaya yang dimiliki oleh mereka sebelum terlibat secara aktif dalam bidang politik. Antara kerjaya mereka ialah pensyarah, guru, wartawan, usahawan, akauntan serta peguam. Oleh itu, tahap pendidikan yang tinggi dalam kalangan informan ini adalah merupakan salah satu agen sosialisasi politik penting yang telah mempengaruhi mereka untuk terlibat dalam bidang politik. Hal ini kerana bagi individu yang mempunyai tahap pendidikan yang tinggi, mereka sangat peka mengenai hak-hak rakyat dan mempunyai kesedaran untuk memperjuangkan nasib mereka melalui bidang politik. Individu yang mempunyai tahap pendidikan yang rendah kurang cenderung untuk bergiat aktif dalam bidang politik. Hal ini kerana individu dari golongan kelas bawahan kebanyakannya lebih berminat untuk terlibat dalam aktiviti yang boleh menjana pendapatan berbanding terlibat dalam bidang politik. Tahap pendidikan yang rendah disebabkan kurangnya ilmu pengetahuan mengenai kepentingan terlibat dalam bidang politik telah memberi kesan yang mempengaruhi persepsi dan tingkah laku politik individu dan masyarakat seterusnya telah memberikan kesan kepada budaya politik kumpulan

\section{b) Status Ekonomi}

Ekonomi juga merupakan antara agen sosialisasi politik penting yang mempengaruhi tingkah laku politik individu. Faktor ekonomi ini adalah merujuk kepada jumlah pendapatan individu. Kebanyakan informan yang telah ditemu bual adalah dalam kalangan individu yang mempunyai economy independence kerana memiliki tahap pendidikan yang tinggi menyebabkan mereka mempunyai kerjaya yang baik seterusnya status ekonomi yang baik sebelum menceburi bidang politik. Status ekonomi yang baik telah mendorong informan untuk bergiat aktif dalam bidang politik. Hal ini kerana economy independence menyebabkan informan tidak bergantung kepada mana-mana individu dalam membuat keputusan termasuklah untuk terlibat aktif dalam bidang politik.

Dalam konteks ini, penyelidik melihat status pendidikan akan mempengaruhi pekerjaan informan. Tahap pendidikan yang tinggi membolehkan informan mendapat pekerjaan yang baik. Pekerjaan yang baik mendatangkan pulangan gaji yang lumayan kepada informan. Pulangan gaji yang lumayan ini telah menimbulkan economy independence dalam kalangan informan. Dalam konteks ini, informan terdiri dalam kalangan pensyarah, wartawan, guru serta akauntan. Menurut informan, faktor economy independence ini membolehkan wanita terlibat dalam public life. Peranan mereka tidak lagi terhad kepada home pick atau home maker. Malah wanita boleh terlibat dalam bidang politik. Oleh itu, status ekonomi merupakan antara agen sosialisasi politik yang memberi kesan ke atas persepsi wanita dalam bidang politik. Rangka pemikiran serta persepsi ini memberi kesan ke atas tingkah laku politik individu seterusnya budaya politik wanita Cina di Semenanjung Malaysia. Menurut Raga Maran (2001:136), proses sosialisasi politik merupakan suatu proses untuk memperkenalkan sistem politik 
kepada individu dan bagaimana individu tersebut menentukan tanggapan serta reaksi-reaksinya terhadap situasi politik.

\section{c) Gender}

Hasil temu bual bersama informan ini menunjukkan bahawa isu gender juga mempengaruhi wanita Cina dalam bidang politik. Hal ini kerana berdasarkan rangka pemikiran bahawa lapangan politik adalah lebih bersesuaian dengan golongan lelaki. Sikap wanita yang lemah lembut dikatakan menjadi penyebab kepada ketidakreleven untuk golongan wanita terlibat dalam bidang politik yang dilabel sebagai keras, masculine dan kotor oleh segelintir individu. Menurut informan, dunia politik dilabel sebagai keras dan masculine tidak sesuai dengan sifat kelembutan yang ada pada wanita. Persepsi ini timbul disebabkan sifat biologi dan keupayaan fizikal yang mempengaruhi persepsi individu ke atas penglibatan wanita dalam bidang politik. Oleh itu, rangka pemikiran ini juga mempengaruhi budaya politik wanita Cina kerana lapangan politik dianggap tidak sesuai untuk wanita.

\section{d) Keluarga}

Keluarga merupakan antara elemen penting yang mempengaruhi kehidupan individu dan merupakan salah satu agen sosialisasi politik yang penting. Oleh itu, bagi kebanyakan informan yang sudah berkahwin, restu dan sokongan suami merupakan faktor penting yang akan memberi impak kepada kerjaya politik mereka namun bagi informan yang belum berkahwin restu dan sokongan ibu bapa dan ahli keluarga yang lain sudah pasti akan memberi kesan kepada kerjaya politik mereka. Melalui hasil temu bual dengan semua informan, kebanyakan mereka mengakui telah mendapat sokongan keluarga. Namun begitu, terdapat kes di mana pada awal pembabitan informan dalam bidang politik, mereka telah mendapat tentangan daripada ahli keluarga mereka.

\section{e) Budaya}

Budaya merupakan suatu cara hidup yang berkembang dan dimiliki bersama oleh sebuah kelompok individu dalam masyarakat dan diwariskan secara turun temurun dari generasi ke generasi. Budaya terbentuk dari pelbagai unsur yang merangkumi agama, politik, adat resam, bahasa, pakaian, bangunan, dan karya seni (Santoso, 2017, p.1). Manakala Itulua (2014:1) berpendapat bahawa budaya merujuk kepada amalan cara hidup anggota masyarakat atau kumpulan dalam masyarakat yang merangkumi cara berpakaian, adat perkahwinan, bahasa, kehidupan berkeluarga, corak pekerjaan, upacara keagamaan dan aktiviti riadah. Oleh itu, dapat disimpulkan bahawa budaya merupakan amalan cara hidup yang diwarisi secara turun temurun dan merangkumi aktiviti sosial, ekonomi, politik dan keagamaan. Budaya politik merupakan salah satu elemen budaya. Namun budaya dalam konteks politik.

Kebanyakan informan menyatakan bahawa tidak ada kekangan dari amalan budaya yang menghalang penglibatan mereka dalam bidang politik. Menurut kebanyakan informan walaupun unsur budaya patriarki Cina masih terdapat dalam masyarakat namun unsur ini semakin menipis seiring peredaran masa dan zaman. Keterbukaan masyarakat Cina terhadap penglibatan wanita dalam bidang politik dapat dilihat melalui jumlah wanita Cina yang telah terpilih menjadi ahli DUN serta ahli Parlimen. Bukti ini dapat dilihat melalui pelantikan pemimpin wanita muda seperti Chua Wei Kiat yang berusia 26 semasa dilantik sebagai ADUN Rawang dari Parti Keadilan Rakyat (PKR). Antara pemimpin wanita muda daripada parti DAP ialah Jamaliah Jamaluddin, Yeo Bee Yin serta Michelle Ng. Malahan menurut informan, "performance" lebih diberi keutamaan oleh masyarakat jika dibandingkan dengan faktor seniority.

Prestasi calon wanita dikatakan lebih baik oleh informan kerana mereka dilabel sebagai lebih bersih, kurang terlibat dalam politik kotor, kurang rasuah, lebih setia dan lebih "genuine" dalam menjalankan tugas yang diberikan menjadi antara faktor mereka diterima sebagai pemimpin politik yang merentas status gender dan status perkahwinan mereka. Jika diteliti, Nicole Wong Siaw Ting seorang wanita muda pertama yang telah berjaya merobohkan dominasi lelaki sebagai Ketua Pemuda MCA. Beliau yang sebelum ini menyandang jawatan sebagai Naib Ketua Pemuda MCA telah berjaya memperoleh 
136 undi sekaligus menewaskan pencabarnya $\mathrm{Ng}$ Kian Nam dalam Pemilihan Jawatankuasa Pusat Pemuda bagi 2018 hingga 2021. ${ }^{\mathrm{i}}$ Fenomena ini menunjukkan wanita sudah mula diterima sebagai ketua di peringkat parti politik yang berasaskan etnik Cina ini melalui undian dalam parti. Malahan Nicole Wong Siaw Ting telah berjaya mengalahkan ahli politik lelaki iaitu Ng Kian Nam dan seterusnya berjaya menyandang jawatan ini buat julung kalinya.

\section{f) Agama}

Sebahagian besar masyarakat Cina di Malaysia menganut agama Buddha yang dibawa bersama oleh imigran Cina dari Tanah Besar China. Dalam konteks ini, agama Buddha telah dibawa oleh Gautama Buddha dari India. Prinsip agama Buddha, kesengsaraan dalam hidup dunia adalah disebabkan oleh kejahilan dalam fikiran yang salah dan tindakan yang salah untuk mencapai Nirvana. Agama Buddha juga menekankan konsep "cycle of life" iaitu manusia akan terus lahir, mati dan lahir semula. Kebanyakan informan yang telah ditemubual adalah dalam kalangan wanita Cina dan menganut agama Buddha dan Kristian. Menurut informan, agama yang dianuti oleh mereka iaitu Budha dan Kristian tidak menghalang untuk wanita melibatkan diri dalam bidang politik.

Definisi agama menurut Berger (1967) adalah satu set kepercayaan yang menghubungkan individu dengan sebuah komuniti dan melangkaui hak dan batas individu. Jika ditelusuri dengan kenyataan informan, agama Buddha dan Kristian menekankan aspek equal untuk semua hidupan sama ada binatang atau manusia, termasuklah lelaki dan juga wanita. Fenomena ini membolehkan wanita bersama-sama dengan lelaki untuk terlibat dalam lapangan politik. Namun menurut informan, lelaki lebih mendominasi institusi agama. Hal ini dapat dilihat melalui individu yang mengendalikan kuil masyarakat Cina. Wanita dianggap tidak bersih semasa haid, dan semasa datang haid mereka tidak boleh masuk ke kuil, tidak boleh bersembahyang serta berdoa.

Agama merupakan agen sosialisasi penting kepada individu semenjak dari mereka kecil. Hal ini kerana, cara untuk hidup juga ditentukan melalui indikator agama termasuklah cara berpolitik. Sekiranya agama menyekat kebebasan untuk wanita terlibat dalam bidang politik, maka sudah pasti fenomena ini akan terkesan dalam kelompok masyarakat yang menganuti agama tersebut. Sebagai contoh, parti PAS yang merupakan parti berlandaskan agama, sebelum ini mengambil pendekatan membenarkan penglibatan wanita dalam bidang politik namun tidak membenarkan wanita memegang jawatan dalam parti politik seperti yang telah diputuskan dalam Muzakarah PAS pada 4 Januari 1953. Pendirian PAS sebagai parti Islam ini berpandukan kepada dasar al-siyasah al syariah iaitu bergantung kepada maslahah dan situasi setempat serta perubahan zaman yang berbeza. Kini, PAS mula memberi peluang kepada calon wanita selepas Dewan Muslimat Pas Pusat (DMPP) mengemukakan usul yang mempertimbangkan calon wanita. Usul ini kemudian diluluskan dalam Muktamar Tahunan Pas ke-44, pada 2 sehingga 4 Jun 2000 (Zaireeni, 2019, p.66-67). ii

Dalam konteks ini, agama dan kepercayaan merupakan agen sosialisasi politik yang penting kerana ia mampu mengkonstruk minda individu seterusnya memberi kesan kepada kehidupan mereka termasuk penglibatan dalam bidang politik. Pengasingan antara elemen agama dan politik di Malaysia tidak terjadi. Hal ini kerana, agama rasmi Malaysia adalah agama Islam. Namun begitu, penduduk Malaysia bebas untuk menganut mana-mana agama. Perkara yang berkaitan agama merupakan isu sensitif di Malaysia. Sebarang perkara yang dianggap mengancam agama akan dipertahankan. Malahan, pengenalan tulisan jawi di sekolah vernakular turut dikecam oleh masyarakat Cina di Malaysia. Perkara ini dibimbangi bermotifkan gerakan Islamisasi orang Islam terhadap pelajar bukan Islam. Dalam konteks ini, Persekutuan Persatuan Lembaga Pengurus Sekolah Cina Malaysia (Dong Zong) telah menyerahkan memorandum penolakan pembelajaran tulisan Jawi di sekolah vernakular kepada Kementerian Pendidikan. Memorandum ini diserahkan oleh Pengerusi Dong Zong, Tan Tai Kim, bersama dua pertubuhan Tamil iaitu CHILD Information, Learning and Development Centre dan Tamil Foundation. ${ }^{\text {iii }}$ Agama merupakan indikator penting kepada masyarakat di Malaysia. Oleh itu, elemen agama sangat berpengaruh dalam kehidupan masyarakat Malaysia secara keseluruhnya termasuklah dalam bidang politik. Dalam konteks ini, indikator agama yang dianuti oleh informan tidak menghalang wanita Cina untuk terlibat dalam lapangan politik. ${ }^{\text {iv }}$ Namun begitu, agama merupakan isu sensitif kepada masyarakat Cina terutamanya berkaitan gerakan Islamisasi. Ini 
menunjukkan bahawa masyarakat Cina masih belum meraikan budaya anak watan dan menolak usaha Dasar Kebudayaan Negara. Tindakan Dong Zong jelas mewakili masyarakat Cina yang masih terbelenggu dalam nilai tradisi yang tidak mempercayai kepimpinan Melayu. Kepimpinan Melayu telah memberi banyak kelebihan kepada masyarakat Cina untuk menguasai ekonomi di Malaysia (Amy Chua, 2014).

\section{Agen Lingkaran Luaran}

\section{a) Organisasi NGO/Persatuan}

Melalui hasil temu bual bersama kebanyakan informan yang terlibat dalam dunia politik, penglibatan aktif dalam persatuan atau organisasi bukan kerajaan (NGO) telah memberi pengaruh besar kepada perwakilan politik wanita Cina sebelum mereka terlibat dalam lapangan politik. Penglibatan ini telah mengasah bakat kepimpinan mereka serta cabaran mengurus NGO dengan dana yang terhad. Informan telah memikirkan kaedah yang lebih bermanfaat untuk membantu golongan sasaran iaitu dengan bidang politik. Jika ditinjau dalam konteks ini, bagi negara yang mengamalkan sistem pemerintahan berdasarkan demokrasi seperti Malaysia, negara yang mengamalkan demokrasi akan responsif kepada tuntutan rakyat terutamanya tuntutan dan lobi yang diperjuangkan oleh NGO. Namun begitu, penglibatan kebanyakan informan dalam NGO tidak mampu untuk menyelesaikan masalah yang dihadapi dengan berkesan dan menyeluruh, maka menceburkan diri dalam bidang politik dengan pelbagai sumber yang lebih luas adalah pilihan untuk berbakti kepada rakyat dan masyarakat. Rentetan itu organisasi NGO merupakan antara agen sosialisasi politik yang memberikan kesan kepada tingkah laku politik serta budaya politik wanita Cina di Semenanjung Malaysia.

\section{b) Masyarakat}

Hasil temu bual mendapati bahawa sebahagian besar informan terlibat dalam dunia politik bermula dengan sikap ingin membantu masyarakat. Rentetan dari sikap ingin membantu masyarakat ini, mereka sanggup memikul tanggungjawab sebagai ahli politik demi kepentingan komuniti. Di samping itu, menurut kebanyakan informan, penglibatan mereka dalam bidang politik adalah rentetan dari sikap kesedaran dan tanggungjawab untuk membantu masyarakat. Kebanyakan informan turut peka akan kurangnya penglibatan wanita Cina dalam politik dan fenomena ini telah mendorong mereka menyahut cabaran. Kebanyakan informan juga dengan jelas menyatakan hasrat untuk membantu wanita kerana menurut pandangan mereka hanya wanita yang lebih memahami keperluan wanita kerana sistem perundangan sedia ada kurang peka terhadap wanita, golongan kurang upaya, warga emas dan kanak-kanak. Penulis merasakan sifat altruism yang dinyatakan oleh kebanyakan informan yang telah ditemu bual ini melambangkan bahawa masyarakat Cina amat berdikari, bersedia untuk membantu masyarakat Cina yang memerlukan bantuan tanpa subsidi kerajaan. Jati diri ini membolehkan masyarakat Cina maju dan berupaya membantu masyarakat mereka dan politik menjadi salah satu saluran untuk menjayakan usaha ini secara konsisten.

\section{c) Parti Politik}

Melalui hasil temu bual bersama kebanyakan informan, wanita tidak didiskriminasikan di peringkat parti politik. Malah, parti politik telah memberi peluang untuk wanita menjawat jawatan penting di dalam parti serta terpilih menjadi calon pilihan raya di peringkat DUN serta Parlimen. Menurut informan parti DAP serta PKR telah membentuk kuota sebanyak 30 peratus untuk meningkatkan penglibatan wanita dalam parti. Di samping itu, parti MCA juga turut menyasarkan 30 peratus kuota untuk wanita di peringkat majlis tertinggi parti namun bilangan wanita MCA yang telah terpilih tidak mencapai sasaran kuota seperti yang telah ditetapkan. Walaupun terdapat peningkatan bilangan wanita di peringkat majlis tertinggi parti MCA dari tahun 2016 sehingga tahun 2018. Fenomena ini berbeza dengan parti PKR kerana kuota 30 peratus yang telah dibentuk hampir mencapai sasaran. Hal ini dapat dilihat pada tahun 2018 di mana sebanyak 27.8 peratus wanita telah berjaya terpilih menganggotai majlis tertinggi parti. Manakala parti DAP telah memperkenalkan sistem kuota pada tahun 2014 
DOI: https://doi.org/10.47405/mjssh.v6i8.953

namun bilangan wanita di peringkat majlis tertinggi parti masih tidak mencapai sasaran kuota yang telah ditetapkan. Pada tahun 2016 keperatusan wanita yang telah terpilih di peringkat majlis tertinggi parti adalah sebanyak 10 peratus dan angka ini telah meningkat kepada 15.6 peratus pada tahun 2017 dan 16.1 peratus pada tahun 2018 (Laporan Kementerian Pembangunan Wanita, Keluarga dan Masyarakat: 2019). Oleh itu, dapat dilihat walaupun peluang dan ruang yang telah diberikan oleh parti DAP, PKR dan MCA melalui sistem kuota, bilangan wanita di peringkat majlis tertinggi parti ini masih tidak berjaya mencapai sasaran kuota yang telah ditetapkan. Malahan, parti MCA dan DAP tidak berjaya mencapai walaupun 20 peratus bilangan wanita di peringkat majlis tertinggi parti jika dibandingkan dengan parti PKR.

Informan berkongsi pandangan, jika ingin merobohkan tembok kekuasaan lelaki maka wanita perlu bekerja keras dan membuktikan bahawa mereka layak dipilih sebagai pemimpin parti mahupun untuk bertanding dalam pilihan raya. Ini bermakna, faktor 'the glass ceiling' masih lagi secara halus mempengaruhi parti politik yang dikuasai oleh golongan lelaki untuk memberikan cabaran kepada wanita. Jika diteliti, iklim dalam parti politik juga merupakan antara agen yang mempengaruhi penglibatan wanita dalam politik. Hal ini kerana, penerimaan dan pengiktirafan wanita dalam parti sudah pasti akan memberikan kesan positif dan membantu menggalakkan wanita untuk terus mengembangkan kerjaya dan lapangan ini. Sekiranya ruang dan peluang tidak diberikan oleh parti, maka sudah pastilah wanita tidak mampu untuk berjaya dalam bidang politik kerana peluang mereka menyandang jawatan penting dalam parti serta menjadi calon dalam pilihan raya telah dihalang.

\section{Kesimpulan}

Hasil analisis melalui proses temu bual yang telah dijalankan, elemen agen sosialisasi politik wanita Cina di Semenanjung Malaysia saling bersilang dan mempengaruhi tingkah laku politik serta budaya politik wanita Cina di Semenanjung Malaysia. Model yang telah dibangunkan iaitu Model Agen Sosialisasi Politik Wanita Cina melalui dimensi teori intersectionality membuktikan bahawa agen sosialisasi politik ini sememangnya saling berkait, bersilang dan telah mempengaruhi budaya politik wanita Cina di Semenanjung Malaysia. Budaya politik wanita Cina di Semenanjung Malaysia masih bersifat pasif. Fenomena ini dapat dilihat melalui bilangan wanita Cina di dalam Parlimen dan DUN. Malahan bilangan wanita di peringkat pembuat keputusan dalam parti berorientasikan masyarakat Cina seperti DAP serta MCA masih lagi rendah. Walaupun telah dibentuk 30 peratus kuota untuk wanita.

\footnotetext{
i(https://www.bharian.com.my/berita/politik/2018/11/494369/wanita-pertama-jadi-ketuapemuda-mca 3 Ogos 2019).

ii DMPP ini telah mengemukakan satu kertas cadangan pada 15 April 2001 yang telah menggariskan lima rasional keperluan penglibatan wanita sebagai calon dalam pilihan raya iaitu tiadanya larangan mutlak berdasarkan nas-nas mantap, banyak isu berkaitan wanita perlu disuarakan oleh Muslimat Pas, menyakinkan masyarakat tentang penghormatan PAS terhadap wanita dan kepimpinan muslimat PAS serta keterbatasan ruang untuk muslimat PAS memberi sumbangan dalam lanskap poltik negara (Zaireeni 2019: 67).

iii (https://www.bharian.com.my/berita/nasional/2020/01/643414/dong-zong-serahmemorandum-tolak-belajar-jawi 4 Ogos 2020).

iv Kerajaan Albania antara tahun 1967 dan 1989 adalah contoh rejim Atheis, di mana semua agama, pertubuhan keagamaan, dan amalan keagamaan dilarang malahan sekolah agama ditutup, pihak berkuasa agama dianiaya.
} 


\section{Rujukan}

Ahmad Nidzamuddin Sulaiman. (2002). Budaya Politik Dalam Masyarakat Majmuk Di Malaysia. Dlm. Abdul Monir Yaacob Dan Suzalie Mohamad (Pnyt). Etika Dan Budaya Berpolitik Dari Perspektif Islam. Kuala Lumpur: Insitut Kefahaman Islam Malaysia.

Amir. (2017). Mca Press And Political Agenda. Malaysian Journal Of Media Studies, 7 (1), 101-110.

Amy Chua. (2004). World on Fire: Globalization and Ethnic Hatred. UK: Arrow Book.

Azizan Zainuddin. (2015). Dasar Wanita Negara dalam Mengarusperdanakan Gender: Kajian Sektor Politik dan Pekerjaan. Tesis Dr. Fal. Universiti Kebangsaan Malaysia.

Babbie, E. (2010). The Practice Of Social Research. Edisi Ke-12. Belmont: Wadsworth.

Bastia, T. (2014). Intersectionality, Migration And Development. Progress In Development Studies, 14(3), 237-248.

Bilge, S. \& Collins, P. H. 2016. Intersectionality. Cambridge UK: Polity.

Brown, N. E. 2014. Political Participation Of Women Of Color: An Intersectional Analysis. Journal Of Women, Politics \& Policy, 35(4), 315-348.

Crenshaw, K. (1989). Demarginalizing The Intersection Of Race And Sex: A Black Feminist Critique Of Antidiscrimination Doctrine, Feminist Theory and Antiracist Politics. University Of Chicago Legal Forum: 139-167.

Crenshaw, K. (1990). Mapping The Margins: Intersectionality, Identity Politics and Violence Against Women Of Color. Stanford Law Review, 43, 1241.

Crenshaw, K. (1991). Mapping The Margins: Intersectionality, Identity Politics and Violence Against Women Of Color. Stanford Law Review, 43(6), 1241-99. dari laman web http://www.jkkn.gov.my/ms/masyarakat-cina-0

Dwijayanto, Arik, Yusmicha Ulya Afif, \& Khoirul Fathoni. 2020. Managing Democracy in Malaysia (Identity, Minorities, and Representation). ARISTO, 8.1(2020), 185-204.

Fahmy Azril Rosli. (2018). Dimuat turun pada 3 Ogos 2019 dari laman web (https://www.bharian.com.my/berita/politik/2018/11/494369/wanita-pertama-jadi-ketua-pemudamca

Fathi, M. (2017). Intersectionality, Class And Migration: Narratives Of Iranian Women Migrants In The Uk. London: Royal Holloway University.

Fatimi. 2019. Penyertaan Wanita Melayu Dalam Mendepani Cabaran Pilihan Raya. Dlm. Kartini \& Zaireeni (pnyt). Penglibatan Wanita Dalam Pilihan Raya, hlm. 99-116. Bangi: Universiti Kebangsaan Malaysia.

Finlay, R., \& Hopkins, P. (2019). Young Muslim Women's Political Participation In Scotland: Exploring The Intersections Of Gender, Religion, Class And Place. Political Geography 74.

Freidenvall, L. (2016). Intersectionality And Candidate Selection In Sweden. Politics, 36(4), 355-363.

Great, J. Jali. Mfm, Fauzi \& Ghazali. 2012. Revision Of The Revenue Act Of 2003 and The Rise To The Public Opposition (GE) 2008 in DUN. The Reboundary Of Electoral Area Constituency 2008 Of Kajang and Bangi, 7 (1), 200.

Hankivsky, O. (2012). Women's Health, Men's Health, And Gender And Health: Implications Of Intersectionality. Social Science \& Medicine, 74(11), 1712-1720.

Ilyas Abdullah. (2020). Mengkaji Mengenai Transformasi Budaya Politik Melayu Terengganu. Tesis Dr, Fal. Universiti Kebangsaan Malaysia.

Ishak Saat. (2014). Tun Abdul Razak Hussein: Survival Politik Melayu 1963-1976. Perspektif: Jurnal Sains Sosial Dan Kemanusiaan, 6(3), 122-137.

Itulua, A. (2014). Sociological Concepts Of Culture and Identity.

ITV News. (2019). Dimuat turun pada 16 Ogos 2020 dari laman web https://www.youtube.com/watch?v=NuuIoJGPjBA

James Chin \& Taufiq Tanasaldy. (2019). The Ethnic Chinese in Indonesia and Malaysia. The Challenge of Political Islam. Asian Survey, 59(6), 959-977.

James Chin. (2001). Malaysian Chinese Politics in The 21st Century: Fear, Service and Marginalisation. Asian Journal of Political Science 9(2): 78-94.

Jang, S. (2018). The Implications Of Intersectionality On Southeast Asian Female Students' Educational Outcomes In The United States: A Critical Quantitative Intersectionality Analysis. American Educational Research Journal, 55(6), 1268-1306. 
Johari Yap. (2019). Dimuat turun pada 16 Ogos 2020 dari laman web (https://www.sinarharian.com.my/article/51854/KOLUMNIS/Yin-dan-yang-dalam-Islam 16 Ogos 2020).

Joshi, D. (2011). Gender And Political Participation: Intersectional Consciousness In The Central Himalayas. The Indian Journal Of Political Science, 72(2), 445-452.

Junaidi Awang Besar \& Mohd Fuad Mat Jali. (2015). Jurnal Personalia Pelajar, 18(1), 11-22.

Junaidi Awang Besar. (2017). Tingkah Laku Pengundi dan Pilihan Politik di Kawasan Parlimen Pasir Mas, Kelantan (Behavior Of Voters And Political Choice In The Parliamentary Area Of Pasir Mas, Kelantan). Geografia Malaysian Journal of Society and Space, 13 (3), 97-111.

Kartini Khalid. 2014. Women And Politics: Social Construction and a Policy of Deconstruction. Journal Of Social Sciences, 10(3), 104.

Kartini. (2019). Merentasi Naratif Partisipasi. Dlm. Kartini \& Zaireeni (pnyt). Penglibatan Wanita Dalam Pilihan Raya, hlm. 99-116. Bangi: Universiti Kebangsaan Malaysia.

Kikue Hamayotsu. (2013). Towards A More Democratic Regime And Society? The Politics Of Faith And Ethnicity In A Transitional Multi-Ethnic Malaysia. Journal Of Current Southeast Asian Affairs, 32(2), 61-88.

Ku Hasnita, Zatul Himmah, Mahadee \& Jayum. (2018). SKP2102 Kenegaraan Malaysia. Serdang: Universiti Putra Malaysia.

Ku Hasnita. (2007). Pemupukan Semangat Patriotisme Melalui Proses Sosialisasi Politik. Journal of Southeast Asian Studies, 2007(12), 131-145.

Laman Web Rasmi Jabatan Kebudayaan dan Kesenian Negara. Dimuat turun pada 10 September 2020

Lee Yok Fee. (2010). Changes In Chinese's Political Involvement In Malaysia. Pertanika Journal Of Social Sciences and Humanities 18(1), 11-21.

Lok Chong Hoe. (1998). Tamadun Cina: Falsafah, Pandangan Dunia, dan Aspek-aspek Kesenian. Pulau Pinang: Universiti Sains Malaysia.

Maznah Mohamad, 2008. Malaysia: Democracy and the end of ethnic politics? Australian Journal of International Affairs, 62(4), 441-459.

Mohammad Agus, Athambawa Sarjoon \& Shameer Othman. (2016). Parliamentary Democracy And Representation Of Women: A Comparative Analysis Of Sri Lanka and Malaysian Stances. Academic Journal of Interdisciplinary Studies, 5.1 (2016), 111.

Mohd Faidz Mohd Zain, Jamaie Hj. Hamil, Mohd Rizal Mohd Yaakob \& Mohamad Rodzi Abd Razak. (2011). Pengaruh Nasionalisme Melayu Mewarnai Budaya Politik Melayu Dalam UMNO (Influences Of Malay Nationalism In Cultural-Politics Of Umno). Jurnal Melayu, (7), 193-216.

Mohd Mahadee Ismail. (2018). Budaya Politik Kontemporari Masyarakat Melayu di Semenanjung Malaysia: Satu Penilaian Kritis. Jurnal Sultan Alauddin Sulaiman Shah, Special Issue (2018), 470-482.

Moreau, J., Pérez, N. \& Sanchez, L. M.. (2019). Intersectionality, Linked Fate, And Lgbtq Latinx Political Participation. Political Research Quarterly, 72(4), 976-990.

Nan Xia, Yok Fee Lee \& Adlina Hj. Ab. Halim . (2018). The Elites' Collective Subjectivities Of The History Of Ethnic Politics In Malaysia. Asian Ethnicity, 1-15, 168-182

Noor Sulastry Yurni. (2014). Hegemoni Budaya Politik Melayu. Bangi: Universiti Kebangsaan Malaysia.

Nor Azura Md Amin. (2019). Dimuat turun pada 17 September 2020 dari laman web (https://www.sinarharian.com.my/article/9956/BERITA/Nasional/Anak-wajib-dapat-pendidikanrendah-menengah).

Nor Rafidah Saidon, Sity Daud \& Mohd Samsudin. 2017. Penglibatan Politik: Pemerkasaan Kepimpinan Wanita Di Malaysia (1980-2013). Jurnal e-Bangi, 12(1), 137-150.

Noraini M. Noor. (2009). The Future Of Malay Chinese Relations Malaysia. Peace Psychology In Asia Springer: 161-172.

Nur Syakiran \& Zawiyah Mohd Zain. (2019).Wanita dan Politik: Analisis Pilihan Raya Umum Malaysia ke-14. Dlm. Kartini \& Zaireeni (pnyt). Penglibatan Wanita Dalam Pilihan Raya, hlm. 99-116. Bangi: Universiti Kebangsaan Malaysia.

Oh Ei Sun. (2014). Malaysian Chinese in a transitioning Malaysia. The 13th Malaysia Elections: Issues, Trends and Future Trajectories. Singapore: S. Rajaratnam School of International Studies. 
Parlimen Malaysia. (2020). Dimuat turun pada 1 September 2020 dari laman web https://www.parlimen.gov.my/

Raga Maran. (2001). Pengantar Sosiologi Politik. Jakarta: Pt.Rineka Cipta.

Rashila Ramli. (1998). Pembangunan politik dan gender: cabaran dan strategi bagi calon-calon wanita. Dlm. Rokiah Talib \& Thambiah, S. (pnyt.). Gender, Budaya dan Masyarakat. hlm. 152-162. Kuala Lumpur: Universiti Malaya.

Rashila Ramli. (1999). Gender Dan Politik: Satu Penelitian Teoretis Dan Empris. Dlm. Ghazali Mayudin (Pnyt.). Teori Sains Politik Pilihan: Aplikasinya Dalam Konteks Malaysia. Bangi: Universiti Kebangsaan Malaysia.

Rashila Ramli. (2008). Pemerkasaan Wanita dalam Politik Malaysia: Pengamatan dan Analisis. Jurnal Kajian Politk dan Masalah Pembangunan (Indonesia), 4 (1), 185-194.

Ridhuan Tee Abdullah. (2008). Persepsi Pelajar Cina Di Institusi Pengajian Tinggi Terhadap Gerakan Politik Umno. Tesis Dr. Fal. Universiti Putra Malaysia.

Ruhana Padzil 2017. Perjuangan Wanita dalam Aktivisme Sosial dan Nasionalisme di Tanah Melayu, 1929-1957. Tesis Dr. Falsafah. Universiti Malaya.

Samadi Ahmad. (2020). Dimuat turun pada 4 Ogos 2020 dari laman web https://www.bharian.com.my/berita/nasional/2020/01/643414/dong-zong-serah-memorandumtolak-belajar-jawi

Samuels, G. M., \& Ross Sheriff, F. 2008. Identity, Oppression, and Power: Feminisms and Intersectionality Theory.

Santoso, T. D. (2017). Apa Itu Budaya. Skp Unair.

Sapiro, V. (2004). Not Your Parents, Political Socialization: Introduction For A New Generation. Annual Review Of Political Science, 7(1), 1-23.

Siti Rohana Omar, Norun Najjah Ahmat, Nor Fazilah Abdul Hamid \& Zanariah Jano. (2008). Sosialisasi Politik Pasca Pilihan Raya Ke-12. Prosiding Seminar Politik Malaysia.

Suhana \& Kartini. (2017). Civil Disobedience Dalam Kalangan Pengundi Cina Di Malaysia (Civil Disobedience Of The Malaysian Chinese Voters). Geografia-Malaysian Journal of Society and Space 7(5), 55-65.

Sukhani, P. 2020. Women's Political Representation: Progressing In Malaysia?. Rsis Commentaries 009-20.

Syarifah Syahirah \& Ummu Atiyah. (2019). Wanita dan Politik: Analisis Pilihan Raya Umum Malaysia ke-14. Dlm. Kartini \& Zaireeni (pnyt). Penglibatan Wanita Dalam Pilihan Raya, hlm. 99-116. Bangi: Universiti Kebangsaan Malaysia.

Tan, G. C. (2014). Pelacur Imigran Cina Di Pulau Pinang. Pulau Pinang: Penerbit Universiti Sains Malaysia.

Taylor, S.J \& Bogdan, R. (1998). Introduction to qualitative Research Methods: A Guidebook and Resource. New York: John Wiley and Sons Inc.

Thock Ker Pong \& Tan Yen Yee. 2018. Urban Tsunami Dalam Pru Ke-13: Analisis Pola Pengundian Masyarakat Cina Malaysia (Urban Tsunami In Ge-13: Analysis On The Voting Patterns Of Malaysian Chinese Voters). Journal Of Chinese Literature and Culture, 6(1), 56-77.

Thornton, A., \& Lin, H. S. (1994). Social Change And The Family In Taiwan. London: University Of Chicago Press.

Wei-An Yang. (2014). Female Emancipation in a Colonial Context: The Chinese Community In Singapore 1900-1942 . Tesis Dr. Falsafah. The University of Sheffield.

Yingying, S. U. (2016). The Sprout and Development of Chinese Classical Culture in Malaya During The 20th Century: Fields and Influences. Journal of Chinese Literature and Culture 4(1): 85-97.

Zaireeni Azmi. (2019). Pilihan Raya Umum ke-14: Keberadaan Muslimat PAS dalam Politik. Dlm. Kartini \& Zaireeni (pnyt). Penglibatan Wanita Dalam Pilihan Raya, hlm. 99-116. Bangi: Universiti Kebangsaan Malaysia. 